\title{
Model Pengaruh Dwelling Time terhadap Biaya Logistik di Terminal Petikemas Makassar
}

\author{
Milwan Kamil*1, Misliah Idrus ${ }^{1}$, Syarifuddin Dewa ${ }^{1}$ \\ ${ }^{1}$ Departemen Teknik Perkapalan, Fakultas Teknik, Universitas Hasanuddin, Makassar \\ Jl. Poros Malino Km. 6, Bontomarannu, Kabupaten Gowa, Sulawesi Selatan, 92171 \\ *Email: milwan.sblmks@gmail.com
}

DOI: 10.25042/jpe.052018.15

\begin{abstract}
Abstrak
Pelabuhan berperan penting dalam sistem transportasi maritim internasional dan logistik suatu negara karena apabila kinerja operasional pelabuhan tidak optimal seperti waktu tunggu sandar dan dwelling time yang masih lama, fasilitas terminal dan tenaga kerja bongkar muat kurang memadai dapat menghambat proses distribusi barang di pelabuhan. Terminal Petikemas Makassar sebagai bagian dari Pelabuhan Makassar merupakan pusat pelayaran kawasan Timur Indonesia yang didukung oleh hinterland Sulawesi Selatan yang potensial. Penelitian ini bertujuan untuk menjelaskan dan membuat model hubungan antara $d$ welling time dengan biaya logistik di Terminal Petikemas Makassar. Biaya logistik dalam penelitian ini adalah biaya tunggu modal dan container port charges yaitu biaya-biaya yang dikeluarkan dalam pengurusan peti kemas di Terminal Petikemas Makassar. Dwelling time adalah jarak waktu dari mulai suatu peti kemas dibongkar dan diangkat dari kapal sampai peti kemas tersebut meninggalkan terminal melalui pintu utama. Penelitian ini menggunakan metode regresi dengan menggunakan software GMDH Shell untuk pemodelan hubungan antara dwelling time dan biaya logistik. Komoditi ekspor dan impor terbesar dijadikan sampel dalam penelitian ini. Hasil penelitian ini menunjukkan tingkat korelasi, pengaruh dwelling time terhadap total biaya logistik baik untuk komoditi ekspor dan impor di Terminal Petikemas Makassar sebesar $100 \%$ dengan model hubungan TLC $=733400+211700 \mathrm{DT}+\mathrm{P}+0,5006 \mathrm{BM}$ untuk komoditi ekspor dan TLC $=733400$ +119700 DT + P + 0,507 BM + GE untuk komoditi impor.
\end{abstract}

\begin{abstract}
Model of Effect of Dwelling Time on Logistics Costs at Makassar Container Terminal. The port plays an important role in the international maritime transport and logistic system on a country because if the port's operational performance is not optimal as the waiting time, the dwelling time is long, terminal facilities and unloading of inadequate work can hamper the process on distribution of the container at the port. Makassar Container Terminal as a part of Makassar Port is an East Indonesia shipping center is supported by a potential South Sulawesi hinterland. This study aimed to explain and make a model of the relationship between dwelling time and logistics costs in Makassar Container Terminal. Logistics costs in this study are waiting capital cost and container port charges, which is expenses incurred in container handling at Makassar Container Terminal. Dwelling time is the time from when the cargo is unloaded from a vessel to when it leaves the gates of the port. This study was conducted by regression method using GMDH Shell software to modeling the relationship between dwelling time and logistic cost. The biggest commodities value in export and import are taken as the sample in this study. The results show that the correlations and influence levels of dwelling time to total logistic costs both export and import comodities in Makassar Container Terminal are $100 \%$ with the models of relations are TLC $=733400+211700$ DT + P + $0,5006 \mathrm{BM}$ for export comodity and TLC $=733400+119700 \mathrm{DT}+\mathrm{P}+0,507 \mathrm{BM}+\mathrm{GE}$ for import comodity.
\end{abstract}

Kata Kunci: Biaya logistik, dwelling time, petikemas, regresi, terminal

\section{Pendahuluan}

Kinerja logistik suatu negara dalam mendukung perdagangan, baik domestik maupun internasional sangat penting bagi pertumbuhan ekonomi dan daya saing karena dengan kinerja logistik yang baik dan efisien dapat menjadi faktor kunci dari pertumbuhan ekonomi yang berkelanjutan [1]. Negara-negara dengan Produk Domestik Bruto (PDB) per kapita yang rendah cenderung mempunyai kinerja logistik yang rendah dan masih memerlukan perbaikan pada aspek pembentuk kinerja logistik dalam Logistics Performance Index [2]. Indonesia saat ini menghadapi tantangan berupa tingginya biaya logistik serta lamanya waktu yang dibutuhkan 
untuk melakukan aktivitas di bidang logistik. Hal ini juga diperkuat dengan studi Bank Dunia [3] menyatakan bahwa rata-rata biaya logistik Indonesia adalah 25,7\% terhadap PDB, lebih besar dari Thailand dan Malaysia, masing-masing sebesar $13,2 \%$ dan $13 \%$.

Pelabuhan berperan sangat penting dalam sistem transportasi maritim internasional dan sistem logistik suatu negara karena apabila kinerja operasional pelabuhan tidak optimal seperti waktu tunggu sandar dan $d w e l l i n g$ time yang masih lama, fasilitas terminal dan tenaga kerja bongkar muat yang kurang memadai dapat menghambat proses distribusi barang di pelabuhan [4]. Pemerintah Indonesia telah mengeluarkan kebijakan untuk meningkatkan kinerja rantai logistik yaitu dengan menurunkan dwelling time secara bertahap pada Rencana Pembangunan Jangka Menengah Nasional (RPJMN) 2015-2020, dari 5-6 hari di tahun 2015 hingga 3-4 hari di tahun 2019 [5].

Terminal peti kemas sebagai bagian dari pelabuhan harus memiliki kinerja yang baik sebagai indikator yang dibutuhkan untuk menilai kelancaran operasional terminal peti kemas dalam melayani kegiatan transportasi barang dan pengembangannya [6]. Kriteria kinerja terminal peti kemas salah satunya dapat dilihat dari produktivitas alat bongkar muat. Kemampuan alat bongkar muat yang dimiliki oleh terminal peti kemas harus dapat dimanfaatkan sepenuhnya untuk melakukan kegiatan bongkar muat peti kemas yang keluar masuk terminal [7].

Propinsi Sulawesi Selatan sebagai salah satu pintu gerbang Indonesia harus memiliki kapasitas sarana dan prasarana transportasi yang memadai dan harus ditunjang dengan kinerja transportasi yang optimal [8]. Terminal Petikemas Makassar sebagai bagian dari Pelabuhan Makassar merupakan pusat pelayaran kawasan Timur Indonesia yang didukung oleh hinterland Sulawesi Selatan yang potensial dengan beberapa komodisi ekspor dan impor unggulan seperti kopi, coklat, rumput laut dan lain-lain. Hal ini dibuktikan dengan semakin meningkatnya pertumbuhan arus peti kemas ekspor dan impor tahun 2010-2016 seperti pada Tabel 1 yang menunjukan bahwa hinterland terminal ini memiliki volume komoditas yang cukup besar dan sangat kompetitif [9].

Namun jumlah peralatan bongkar muat yang kurang dan adanya kerusakan alat pada Terminal Petikemas Makassar dapat mengakibatkan terhambatnya distribusi barang dan tingginya biaya logistik sebagai bentuk dari lamanya penanganan kapal dan kontainer di pelabuhan. Hal lainnya adalah perijinan dari instansi yang terkait seperti BPOM, Karantina dan Bea Cukai [10].

Tabel 1. Arus peti kemas

\begin{tabular}{ccc} 
Tahun & Volume & Pertumbuhan \\
\hline 2010 & 442.553 & - \\
2011 & 450.567 & $2 \%$ \\
2012 & 529.316 & $17 \%$ \\
2013 & 550.916 & $4 \%$ \\
2014 & 562.046 & $2 \%$ \\
2015 & 558.957 & $-1 \%$ \\
2016 & 612.208 & $10 \%$ \\
\hline
\end{tabular}

\section{Metode}

\subsection{Biaya Logistik}

Biaya logisitik dalam penelitian ini adalah semua biaya pelayanan dan biaya tunggu selama peti kemas berada di Terminal Petikemas Makassar. Untuk komoditi ekspor, total biaya logistik yaitu seperti Persamaan 1 dan untuk komoditi impor seperti pada Persamaan 2:

$$
\begin{gathered}
T L C=T H C+L O+P+B M \\
T L C=T H C+L O+P+G E+B M
\end{gathered}
$$

dimana TLC adalah total biaya logistik, THC adalah biaya penanganan peti kemas, LO adalah biaya lift off/ lift on, $\mathrm{P}$ adalah biaya penumpukan, GE adalah biaya ekstra dan BM adalah biaya tunggu modal komoditi yang dapat dihitung dengan menggunakan Persamaan 3.

$$
B M=\frac{N B \times 1}{365}
$$

dimana NB adalah nilai modal barang dan i adalah tingkat suku bunga.

\subsection{Dwelling Time}

Dwelling time (DT) adalah jarak waktu dari mulai suatu peti kemas dibongkar dan diangkat 
dari kapal sampai peti kemas tersebut meninggalkan terminal melalui pintu utama [11]. Dwelling time dihitung dengan Persamaan 4 [12].

$$
D T=\frac{\sum(n \times t)}{\sum n}
$$

dimana $\mathrm{n}$ adalah jumlah teus tiap party barang, $\mathrm{t}$ adalah lama hari penumpukan tiap party dan $\sum \mathrm{n}$ adalah jumlah teus barang yang ditumpuk pada periode bersangkutan.

\subsection{Regresi Linear}

Penelitian ini menggunakan explanatory research dengan pendekatan kuantitatif. Explanatory research merupakan penelitian yang bertujuan untuk menelaah kausalitas antar variabel yang menjelaskan suatu fenomena tertentu [11]. Analisis yang digunakan adalah analisis regresi linier sederhana untuk memprediksikan seberapa jauh hubungan fungsional ataupun kausal satu variabel independen dengan satu variabel dependen [13]. Analisis regresi linear sederhana, selain digunakan untuk mengukur kekuatan hubungan antara dua variabel, juga dapat menunjukan arah hubungan antara satu variabel dependen dan satu variabel independen [14]. Persamaan umum regresi linier sederhana dalam penelitian ini adalah:

$$
Y=a+b x+e
$$

dimana Y adalah subyek dalam variabel dependen yang diprediksikan, a adalah konstanta, yaitu besarnya nilai $\mathrm{Y}$ ketika nilai $\mathrm{X}=0$, b adalah perubahan nilai $\mathrm{Y}$ apabila terjadi perubahan nilai $\mathrm{X}, \mathrm{X}$ adalah variabel independen dan e adalah kesalahan prediksi (error).

\section{Hasil dan Pembahasan}

Arus peti kemas di Terminal Petikemas Makassar terdiri atas dua komoditi, yaitu komoditi ekspor dan komoditi impor. Komoditi ekspor yaitu rumput laut, kopi, cokelat, biji mente, plywood, oleo pine resin, carrageenan, coffee bean, marble tiles dan terigu. Komoditi impor terdiri dari keramik, sirup gula jagung, furniture sofa, pakan ternak dan elektronik [9]. Tabel 2 menunjukkan perhitungan biaya tunggu modal per hari per komoditi ekspor dan komoditi impor. Rumput laut memiliki volume terbesar untuk komoditi ekspor dengan biaya tunggu modal Rp. 423.922,- per hari. Pada komoditi impor, keramik memiliki volume terbesar dengan biaya tunggu modal sebesar Rp. 242.892 per hari [9]. Dua komoditi ini diambil sebagai sampel penelitian.

\begin{tabular}{|c|c|c|c|c|c|}
\hline Komoditi & $\begin{array}{c}\text { Jumlah } \\
\text { Kontainer }\end{array}$ & Berat Kotor & Nilai Barang & $\begin{array}{c}\text { Suku } \\
\text { Bunga } \\
\end{array}$ & $\begin{array}{c}\text { Biaya Tunggu Modal } \\
\text { per hari }\end{array}$ \\
\hline \multicolumn{6}{|l|}{ EKSPOR } \\
\hline Rumput laut & 4 & 81360 & 561.384 .000 & $10,25 \%$ & 423.922 \\
\hline Kopi & 1 & 19200 & Rp. 1.669 .248 .000 & $10,25 \%$ & 5.042 .044 \\
\hline Cokelat & 1 & 20400 & Rp. 2.138 .420 .400 & $10,25 \%$ & Rp. $\quad 6.459 .201$ \\
\hline Biji mente & 1 & 16783 & Rp. 2.364 .478 .200 & $10,25 \%$ & Rp. 7.142 .020 \\
\hline Plywood & 2 & 46345 & Rp. $\quad 564.420 .000$ & $10,25 \%$ & 852.429 \\
\hline Oleo pine resin & 2 & 35230 & 434.948 .400 & $10,25 \%$ & 656.891 \\
\hline Carrageenan & 1 & 20000 & 276.000 .000 & $10,25 \%$ & 833.671 \\
\hline Coffee bean & 1 & 18000 & Rp. 1.608 .735 .000 & $10,25 \%$ & Rp. 4.859 .261 \\
\hline Marble tiles & 1 & 19330 & Rp. $\quad 151.951 .800$ & $10,25 \%$ & Rp. $\quad 458.978$ \\
\hline Terigu & 5 & 115000 & 475.479 .000 & $10,25 \%$ & 287.241 \\
\hline \multicolumn{6}{|l|}{ IMPOR } \\
\hline Keramik & 2 & 55800 & 160.826 .342 & $10,25 \%$ & 242.892 \\
\hline Sirup gula jagung & 2 & 46420 & 230.877 .053 & $10,25 \%$ & 348.688 \\
\hline Furniture sofa & 1 & 4167 & 170.466 .711 & $10,25 \%$ & 514.903 \\
\hline Pakan ternak & 3 & 57434 & 444.508 .145 & $10,25 \%$ & 447.553 \\
\hline Elektronik & 1 & 3762 & 201.699 .820 & $10,25 \%$ & 609.244 \\
\hline
\end{tabular}

Tabel 2. Biaya modal per komoditi 
Tabel 3. Biaya logistik komoditi ekspor dan impor pada hari pertama

\begin{tabular}{|c|c|c|c|c|c|c|c|c|}
\hline Komoditi & & THC & LO & $P^{*}$ & $\mathbf{G E}^{* *}$ & & BM & TLC \\
\hline \multicolumn{9}{|l|}{ Ekspor } \\
\hline Rumput laut & Rp. & 623.000,- Rp. & $110.400,-$ & $18.000,-$ & & Rp. & $423.922,-$ & Rp. 1.175.322,- \\
\hline Kopi & $\mathrm{Rp}$. & $623.000,-\mathrm{Rp}$. & 110.400,- & 18.000,-- & & Rp. & 5.042.044,-- & Rp. 5.793.444,- \\
\hline Cokelat & Rp. & 623.000,- Rp. & 110.400,- & $18.000,-$ & & $\mathrm{Rp}$. & 6.459.201,-- & Rp. 7.210.601,- \\
\hline Biji mente & $\mathrm{Rp}$. & 623.000,- Rp. & 110.400,- & $18.000,-$ & & $\mathrm{Rp}$. & 7.142.020,- & Rp. 7.893.420,- \\
\hline Plywood & $\mathrm{Rp}$. & 623.000,- Rp. & 110.400,- & 18.000,- & & Rp. & $852.429,-$ & Rp. 1.603.830,- \\
\hline Oleo pine resin & Rp. & 623.000,- Rp. & 110.400,- & $18.000,-$ & & Rp. & 656.891,- & Rp. 1.408.291,- \\
\hline Carrageenan & $\mathrm{Rp}$. & 623.000,- Rp. & 110.400,- & $18.000,-$ & & Rp. & $833.671,-$ & Rp. 1.585.071,- \\
\hline Coffee bean & $\mathrm{Rp}$. & 623.000,- Rp. & $110.400,-$ & 18.000,- & & Rp. & 4.859.261,-- & Rp. 5.610.661,- \\
\hline Marble tiles & Rp. & 623.000,- Rp. & 110.400,- & 18.000,- & & Rp. & 458.978,- & Rp. 1.210.378,- \\
\hline Terigu & $\mathrm{Rp}$. & $623.000,-\quad \mathrm{Rp}$ & 110.400,- & $18.000,-$ & & Rp. & 287.241,- & Rp. 1.038.641,- \\
\hline \multicolumn{9}{|c|}{ - } \\
\hline Keramik & Rp. & 623.000,- Rp. & 110.400,- Rp. & $18.000,-$ & Rp. & Rp. & 242.892, & 994.292,-- \\
\hline Sirup jagung & Rp. & 623.000,- Rp. & 110.400,- Rp. & 18.000,- & Rp. & Rp. & 348.688, & Rp. 1.448.775,- \\
\hline Furniture sofa & $\mathrm{Rp}$. & $623.000,-\quad \mathrm{Rp}$ & 110.400,- Rp. & $18.000,-$ & $\mathrm{Rp}$. & Rp. & 514.903, & Rp. 1.266.303,- \\
\hline Pakan ternak & Rp. & 623.000,- Rp. & 110.400,- & 18.000,- & Rp. & Rp. & 447.553, & Rp. 1.198.953,- \\
\hline Elektronik & Rp. & 623.000,- Rp. & 110.400,- Rp. & $18.000,-$ & Rp. & Rp. & 609.244,- & Rp. 1.360.644,- \\
\hline
\end{tabular}

Tabel 3 menunjukkan total biaya logistik komoditi ekspor dan impor pada hari pertama di Terminal Petikemas Makassar. Komoditi ekspor tidak dikenakan biaya gerakan ekstra. Komponen biaya konstan terdiri dari biaya THC, LO dan GE tetapi biaya GE baru dikenakan pada hari ketiga. Biaya penumpukan $(\mathrm{P})$ pada hari pertama sampai hari kelima biayanya konstan sebesar Rp. 18.000/hari, tetapi pada hari ke 6 ditambah Rp. 18.000/hari. Demikian juga dengan biaya tunggu modal (BM), yang dihitung berdasarkan Persamaan 3 dan berkelipatan berdasarkan lama hari barang di terminal.

Dwelling time di Terminal Petikemas Makassar berdasarkan data pada bulan AgustusOktober tahun 2017 [9] seperti pada Gambar 1 menunjukkan nilai dwelling time yang fluktuatif tiap bulan. Pada bulan Agustus, dwelling time sebesar 2,62 hari naik sebesar 12,21\% menjadi 2,94 hari pada bulan September dan turun sebesar 14,97\% menjadi 2,50 hari pada bulan Oktober. Jumlah teus peti kemas yang ditumpuk pada periode Agustus 491 Teus menjadi 547 Teus pada bulan September dan 523 Teus pada bulan Oktober cukup berpengaruh pada dwelling time, tetapi pada bulan Oktober menunjukkan adanya peningkatan kinerja operasional Terminal Petikemas Makassar yang lebih baik dari bulan
Agustus dimana jumlah teus peti kemas yang ditumpuk yang lebih besar pada bulan Oktober tetapi nilai dwelling time yang lebih kecil daripada dwelling time pada bulan Agustus.

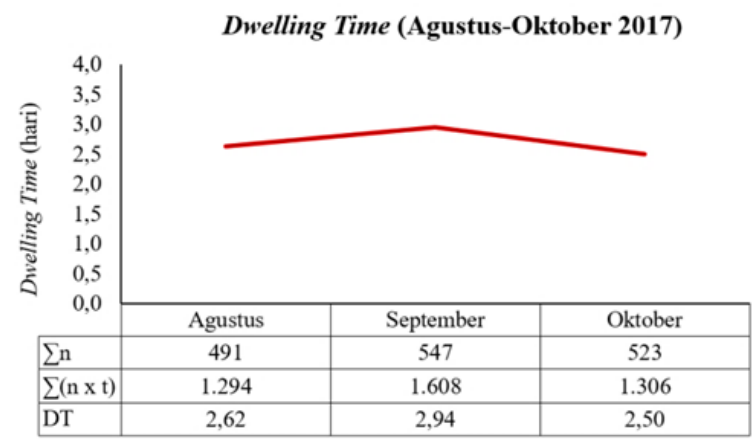

Gambar 1. Dwelling time di terminal petikemas
makassar

Tabel 4 menunjukkan rekapitulasi total biaya logistik untuk komoditi rumput laut berdasarkan nilai dwelling time di Terminal Petikemas Makassar. Berdasarkan data tersebut, kemudian dilakukan regresi linear menggunakan aplikasi GMDH Shell untuk menguji hubungan antara dwelling time dengan total biaya logistik untuk komoditi rumput laut (ekspor). Hasil regresi linear yang diperoleh menunjukkan nilai korelasi dan besarnya pengaruh dwelling time dengan total biaya logistik di Terminal Petikemas Makassar 
yaitu sebesar 100\%. Gambar 2 menunjukkan grafik hubungan antara dwelling time dan total biaya logistik komoditi ekspor rumput laut di
Terminal Petikemas Makassar dengan bentuk persamaan hasil regresi linear yaitu TLC = $733400+211700 \mathrm{DT}+\mathrm{P}+0,5006 \mathrm{BM}$.

Tabel 4. Tabel total biaya logistik komoditi ekspor rumput laut

\begin{tabular}{cllllllllll}
\hline DT & & \multicolumn{1}{l}{ THC } & \multicolumn{1}{l}{ LO } & & P & & BM & & \multicolumn{1}{l}{ TLC } \\
\hline 1 & Rp. & $623.000,-$ & Rp. & $110.400,-$ & Rp. & $18.000,-$ & Rp. & $423.922,-$ & Rp. & $1.175 .322,-$ \\
2 & Rp. & $623.000,-$ & Rp. & $110.400,-$ & Rp. & $18.000,-$ & Rp. & $847.844,-$ & Rp. & $1.599 .244,-$ \\
3 & Rp. & $623.000,-$ & Rp. & $110.400,-$ & Rp. & $18.000,-$ & Rp. & $1.271 .765,-$ & Rp. & $2.023 .165,-$ \\
4 & Rp. & $623.000,-$ & Rp. & $110.400,-$ & Rp. & $18.000,-$ & Rp. & $1.695 .687,-$ & Rp. & $2.447 .087,-$ \\
5 & Rp. & $623.000,-$ & Rp. & $110.400,-$ & Rp. & $18.000,-$ & Rp. & $2.119 .609,-$ & Rp. & $2.871 .009,-$ \\
6 & Rp. & $623.000,-$ & Rp. & $110.400,-$ & Rp. & $36.000,-$ & Rp. & $2.543 .531,-$ & Rp. & $3.312 .931,-$ \\
7 & Rp. & $623.000,-$ & Rp. & $110.400,-$ & Rp. & $54.000,-$ & Rp. & $2.967 .453,-$ & Rp. & $3.754 .853,-$ \\
8 & Rp. & $623.000,-$ & Rp. & $110.400,-$ & Rp. & $72.000,-$ & Rp. & $3.391 .375,-$ & Rp. & $4.196 .775,-$ \\
9 & Rp. & $623.000,-$ & Rp. & $110.400,-$ & Rp. & $90.000,-$ & Rp. & $3.815 .296,-$ & Rp. & $4.638 .696,-$ \\
10 & Rp. & $623.000,-$ & Rp. & $110.400,-$ & Rp. & $108.000,-$ & Rp. & $4.239 .218,-$ & Rp. & $5.080 .618,-$ \\
11 & Rp. & $623.000,-$ & Rp. & $110.400,-$ & Rp. & $126.000,-$ & Rp. & $4.663 .140,-$ & Rp. & $5.522 .540,-$ \\
12 & Rp. & $623.000,-$ & Rp. & $110.400,-$ & Rp. & $144.000,-$ & Rp. & $5.087 .062,-$ & Rp. & $5.964 .462,-$ \\
13 & Rp. & $623.000,-$ & Rp. & $110.400,-$ & Rp. & $162.000,-$ & Rp. & $5.510 .984,-$ & Rp. & $6.406 .384,-$ \\
14 & Rp. & $623.000,-$ & Rp. & $110.400,-$ & Rp. & $180.000,-$ & Rp. & $5.934 .906,-$ & Rp. & $6.848 .306,-$ \\
15 & Rp. & $623.000,-$ & Rp. & $110.400,-$ & Rp. & $198.000,-$ & Rp. & $6.358 .827,-$ & Rp. & $7.290 .227,-$ \\
\hline
\end{tabular}

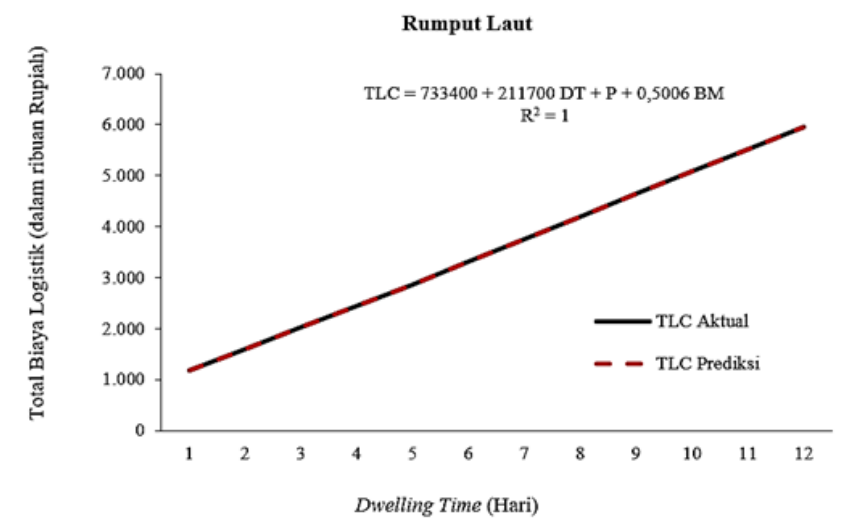

Gambar 2. Hubungan dwelling time dengan total biaya logistik komoditi rumput laut (ekspor)
Tabel 4 menunjukkan rekapitulasi total biaya logistik untuk komoditi impor keramik berdasarkan nilai dwelling time di Terminal Petikemas Makassar. Berdasarkan data tersebut, kemudian dilakukan regresi linear menggunakan aplikasi GMDH Shell untuk menguji hubungan antara dwelling time dengan total biaya logistik untuk komoditi mpor keramik. Hasil regresi linear yang diperoleh menunjukkan nilai korelasi dan besarnya pengaruh dwelling time dengan total biaya logistik di Terminal Petikemas Makassar yaitu sebesar $100 \%$.

Tabel 5. Tabel total biaya logistik komoditi impor keramik

\begin{tabular}{|c|c|c|c|c|c|c|c|c|c|c|c|c|}
\hline DT & & THC & & LO & & $\mathbf{P}$ & & GE & & BM & & TLC \\
\hline 1 & Rp. & $623.000,-$ & Rp. & 110.400, & Rp. & 18.000,- & Rp. & & Rp. & $242.892,-$ & Rp. & 994.292,- \\
\hline 2 & Rp. & $623.000,-$ & Rp. & - & Rp. & 18.000,- & Rp. & & Rp. & $485.784,-$ & Rp. & 184,- \\
\hline 3 & $\mathrm{Rp}$. & $623.000,-$ & Rp. & 110.400, & Rp. & 18.000,- & Rp. & $302.800,-$ & Rp. & $728.676,-$ & Rp. & 876,- \\
\hline 4 & Rp. & $623.000,-$ & Rp. & - & Rp. & 18.000,- & Rp. & 302. & Rp. & $971.567,-$ & Rp. & $.767,-$ \\
\hline 5 & $\mathrm{Rp}$. & $623.000,-$ & Rp. & 110.400, & $\mathrm{Rp}$. & 18.000,- & Rp. & $302.800,-$ & Rp. & 1.214.351,- & Rp. & 2.268.659,- \\
\hline 6 & $\mathrm{Rp}$. & $623.000,-$ & Rp. & & Rp. & 36.000,- & Rp. & $302.800,-$ & Rp. & 1.457.351,- & Rp. & 2.529.551,- \\
\hline 7 & $\mathrm{Rp}$. & $623.000,-$ & Rp. & 110.400, & $\mathrm{Rp}$. & $54.000,-$ & Rp. & $302.800,-$ & $\mathrm{Rp}$. & 1.700.243,- & Rp. & 2.790.443,- \\
\hline 8 & Rp. & $623.000,-$ & Rp. & - & Rp. & $72.000,-$ & Rp. & $302.800,-$ & Rp. & $1.943 .135,-$ & Rp. & $3.051 .335,-$ \\
\hline 9 & Rp. & 623.0 & Rp. & 110.400, & Rp. & $90.000,-$ & Rp. & 302. & Rp. & 2.186.027,- & Rp. & 3.312 \\
\hline 10 & Rp. & $623.000,-$ & Rp. & - & Rp. & $108.000,-$ & Rp. & $302.800,-$ & Rp. & 2.428.918,- & Rp. & $3.573 .118,-$ \\
\hline 11 & Rp. & $623.000,-$ & Rp. & 110.400 & Rp. & $126.000,-$ & Rp. & $302.800,-$ & Rp. & 2.671.810,- & Rp. & 3.834.010,- \\
\hline 12 & Rp. & $623.000,-$ & Rp. & & $\mathrm{Rp}$. & $144.000,-$ & Rp. & $302.800,-$ & Rp. & 2.914.702,- & Rp. & 4.094.902,- \\
\hline 13 & Rp. & $623.000,-$ & Rp. & 110.400, & $\mathrm{Rp}$. & $162.000,-$ & Rp. & $302.800,-$ & Rp. & 3.157.594,- & Rp. & 4.355.794,- \\
\hline 14 & Rp. & $623.000,-$ & Rp. & - & Rp. & $180.000,-$ & Rp. & $302.800,-$ & $\mathrm{Rp}$. & 3.400.486,- & Rp. & 4.616.686,- \\
\hline 15 & Rp. & $623.000,-$ & Rp. & 110.400 & Rp. & $198.000,-$ & Rp. & $302.800,-$ & Rp. & 3.643.378,- & Rp. & 4.877.578,- \\
\hline
\end{tabular}




\begin{tabular}{lllllll}
\hline DT & THC & LO & P & GE & BM & TLC \\
\hline
\end{tabular}

110.400,

110.400,

110.400,

110.400,

110.400,

110.400,

110.400

Gambar 3 menunjukkan grafik hubungan antara dwelling time dan total biaya logistik komoditi ekspor rumput laut di Terminal Petikemas Makassar dengan bentuk persamaan hasil regresi linear yaitu TLC $=733400+119700$ $\mathrm{DT}+\mathrm{P}+0,507 \mathrm{BM}+\mathrm{GE}$.

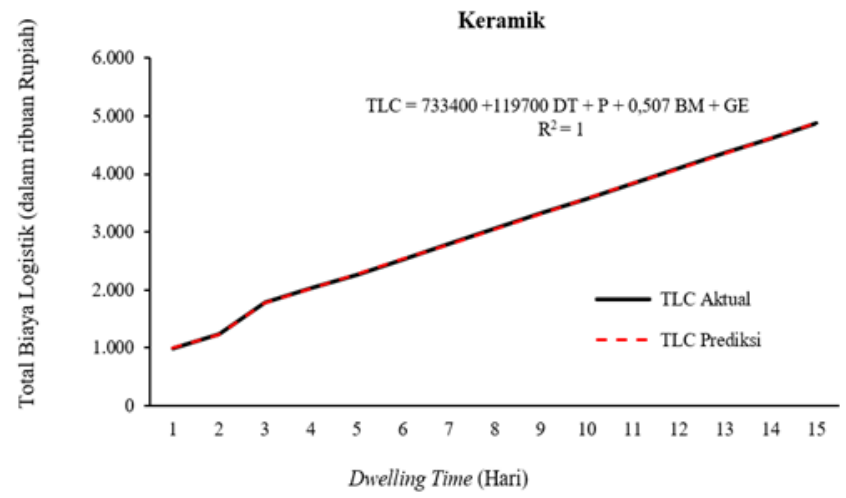

Gambar 3. Hubungan dwelling time dengan total biaya logistik komoditi keramik (impor)

\section{Kesimpulan}

Penelitian ini menggunakan analisa regresi linear dengan software GMDH Shell untuk menjelaskan dan membuat model hubungan pengaruh dwelling time dengan biaya logistik dengan $d$ welling time sebagai variabel bebas $(\mathrm{X})$ dan total biaya logistik sebagai variabel terikat (Y). Dari hasil penelitian yang diperoleh dapat disimpulkan bahwa dwelling time memiliki pengaruh terhadap peningkatan biaya logisitik di Terminal Petikemas Makassar sebesar 100\% untuk komoditi ekspor dan impor. Model hubungan antara dwelling time dan total biaya logistik di Terminal Petikemas Makassar dapat digambarkan melalui persamaan TLC $=733400+$ $211700 \mathrm{DT}+\mathrm{P}+0,5006 \mathrm{BM}$ untuk komoditi ekspor dan TLC $=733400+119700 \mathrm{DT}+\mathrm{P}+$ $0,507 \mathrm{BM}+\mathrm{GE}$ untuk komoditi impor. Hal ini menunjukkan bahwa semakin lama dwelling time maka semakin mahal biaya logistik yang terjadi di Terminal Petikemas Makassar.

\section{Referensi}

[1] Havenga, Jan, 2010, "Logistic Costs in South AfricaThe Case of Macroeconomic Measurement", South African Journal of Economic. Vol. 78.

[2] Popescu, A. C., \& Sipos C., 2014, "Logistic Performance and Economic Development-The Comparison within the European Union", Proceeding of MAC-EMM 2014, ISBN 978-80-905442-8-4.

[3] The World Bank, ITB, Asosiasi Logistik Indonesia \& STC-Group, 2015, "State of Logistics Indonesia 2015", Jakarta.

[4] Bichou, K., Bell, M. G. H. \& Evans, A, 2007, "Risk Management in Port Operations, Logistics and Supply Chain Security”, LLYOD's Practical Shipping Guides, New York.

[5] BAPPENAS, 2015, "Rencana Pembangunan Jangka Menengah Nasional 2015-2019".

[6] Fourgeaud, P., 2000, "Measuring Port Performance", The World Bank Group.

[7] Sudjatmiko, F. D. C., 2006, "Sitem Angkutan Peti Kemas", Janiku Pustaka, Jakarta.

[8] Menhub bakal jadikan sulsel pintu gerbang RI diakses di:https://m.liputan6.com/bisnis/read/3143875/menhub -bakal-jadikan-sulsel-pintu-gerbang-ri/.

[9] PT. Terminal Petikemas Makassar, 2017, "Annual Report 2016".

[10] Karantina ikan lama apiki minta BKIPM percepat layanan diakses di: 
https://m.bisnis.com/industri/read/20170127/karantinaikan-lama-apiki-minta-BKIPM-percepat-layanan

[11] Zulganef, 2008, "Metode Penelitian Sosial dan Bisnis", Graha Ilmu, Yogyakarta.

[12] DITJENHUBLA, "Peraturan Direktur Jenderal Perhubungan Laut No. HK.103/2/18/DJPL-16 tentang Standar Kinerja Pelayanan Operational Pelabuhan yang diusahakan secara Komersial".

[13] Sugiyono, 2009, "Metode Penelitian Bisnis", Alfabeta, Bandung.

[14] Misliah, 2012, “Optimasi Pemanfaatan Lapangan
Penumpukan Petikemas di Pelabuhan Indonesia IV ditinjau dari Kepentingan Operator dan Pengguna", Disertasi Pascasarjana UNHAS, Makassar.

[15] KEMENHUB, "Peraturan Menteri Perhubungan No. PM 23 Tahun 2017 tentang Perubahan atas Perubahan atas Peraturan Menteri Perhubungan No. PM 116 Tahun 2016 tentang Pemindahan Barang yang Melewati Batas Waktu Penumpukan (Long Stay) di Pelabuhan Utama Belawan, Pelabuhan Utama Tanjung Priok, Pelabuhan Utama Tanjung Perak dan Pelabuhan Utama Makassar". 